\title{
Synthesis of 6, 4"'-Di-O-methylerythromycin A and its derivatives
}

\author{
Liquan Sun ${ }^{1, a}$, Bufang Ma ${ }^{2, b}$, Guowei Yao ${ }^{3, \mathrm{c}}$ \\ ${ }^{1}$ School of Life Science, Beijing Institute of Technology, Beijing, 100081, China \\ ${ }^{2}$ School of Life Science, Beijing Institute of Technology, Beijing, 100081, China \\ ${ }^{3}$ School of Life Science, Beijing Institute of Technology, Beijing, 100081, China \\ aemail: slq@bit.edu.cn, bemail:huaweiyirenkai@126.com, ’email: yaoguowei@bit.edu.cn
}

\section{Keywords: Soccer 6,4"-Di-O-methylerythromycin A; Clarithromycin; Synthesis}

\begin{abstract}
Di-O-methylerythromycin A is a relative substance of clarithromycin, which is due to incomplete protection of 4' $-\mathrm{OH}$ during the methylation process. In this study, 6,4' -DiO-methylerythromycin $\mathrm{A}(5)$ and its derivatives including 2'-O-TMS-6-O-methylerythromycin A 9-[(1-ethoxy-1-methylethyl)oxime](2), 2'-O-TMS-6,4''-Di-O-methylerythromycin A 9-[(1-ethoxy1-methylethyl)oxime](3) and 6,4"'-Di-O-methylerythromycin A 9-oxime(4) was synthesized from 2',4''-O-bis(TMS)-6-O-methylerythromycin A 9-[(1-ethoxy-1-methylethyl)oxime](1). The structure of each compound was identified by ${ }^{1} \mathrm{H}-\mathrm{NMR}$ and ${ }^{13} \mathrm{C}-\mathrm{NMR}$.
\end{abstract}

\section{Introduction}

Clarithromycin (6-O-methylerythromycin A), one of the best known macrolide antibiotics, has strong antibacterial activity and good pharmacokinetic properties [1]. Clarithromycin can inhibit H.pylori, which makes it widely used in clinic [2]. Clarithromycin was synthesized after oximation, etherification, silylation, methylation and de-protection with erythromycin A as the starting material in industrial production [3] [4] [5] [6]. There are various relative substances in clarithromycin products [7], whose type and content can be the direct indicator of the product's quality.

Group protection and region-selective methylation are the most important issues in industrial production of clarithromycin [8]. TMS is used as protecting group of 2'-OH and 4' $-\mathrm{OH}$, derivatives of 6,4' -Di-O-methylerythromycin A will form if 4'- $\mathrm{OH}$ isn't protected completely. Furthermore, methylation reaction is accompanied by de-protection reaction. 4' -OTMS is easy to remove under alkaline conditions to form derivatives of 4"'-O-methylerythromycin A in methylation procedure [9]. In this article, we synthesized the clarithromycin relative substance 5 and its derivatives 2, 3 and 4 with 1 as the starting material, the reaction pathway can be seen in Fig.1. Purification of each compound was performed by column chromatography and their structures were determined by ${ }^{1} \mathrm{H}-\mathrm{NMR}$ and ${ }^{13} \mathrm{C}-\mathrm{NMR}$.

\section{Reagents and Instruments}

2',4',-O-bis(TMS)-6-O-methylerythromycin A 9-[(1-ethoxy-1-methylethyl)oxime] was provided by Zhejiang Guobang Pharmaceutical Company. All Reagents and solvents were purchased from Beijing Chemical Reagents Company. ${ }^{1} \mathrm{H}-\mathrm{NMR}$ and ${ }^{13} \mathrm{C}-\mathrm{NMR}$ spectra were recorded in $\mathrm{CDCl}_{3}$ on ARX500 spectrometer. HPLC was carried out on a $4.6 \times 250 \mathrm{~mm}$ column of Purospher STAR LP $\mathrm{RP}-18 \mathrm{e}(5 \mathrm{um})$ with $0.067 \mathrm{M} \mathrm{KH}_{2} \mathrm{PO}_{4}(\mathrm{pH} 4.0)$ buffer/acetonitrile $=55 / 45$.

\section{Synthesis of 2'-O-TMS-6-O-methylerythromycin A 9-[(1-ethoxy-1-methylethyl) oxime](2)}

A solution of $1(5.0 \mathrm{~g}, 5.03 \mathrm{mmol})$ in $50 \mathrm{ml}$ of THF was treated with $4 \mathrm{ml}$ of water and $0.2 \mathrm{~g} 85 \%$ $\mathrm{KOH}$ powder at $25^{\circ} \mathrm{C}$. The solution was monitored by TLC (petroleum ether/ethyl acetate/ diethylamide, 10/1/1). The resultant reaction was added in $20 \mathrm{ml}$ water and then basified $(\mathrm{pH}=9)$ using $\mathrm{NH}_{4} \mathrm{Cl}$ solid. The mixture was extracted with petroleum ether and the organic layer was washed successively with saturated brine and water and dried over $\mathrm{MgSO}_{4}$. The solvent was 
evaporated in vacuo and the residue was crystallized from petroleum ether to afford $3.5 \mathrm{~g}(75.5 \%)$ of 2 as colorless crystals:

${ }^{1} \mathrm{H}-\mathrm{NMR}\left(500 \mathrm{MHz}, \mathrm{CDCl}_{3}\right) \delta(\mathrm{ppm}): 0.12$ ( s, 9H, 2'-OTMS ), 0.85 ( t, 3H, H-15 ), 0.96 ( d, 3H, 8-CH3 ), 1.03 ( d, 3H, 4-CH3 ), 1.24 ( s, 3H, 3''-CH3 ), 1.29 ( d, 3H, 5',-CH3 ), 1.41 [ s, 6H, -O-C(CH3)2-O- ], 1.46 ( m, 1H, H-14 ), 1.48 ( m, 1H, H-4' ), 1.50 ( s, 3H, 6-CH3 ), 1.52 ( m, 1H, H-2' ') 1.57 ( m, 1H, H-7 ), 1.86 ( m, 1H, H-14 ), 1.94 ( m, 1H, H-4 ), 2.19 ( m, 1H, 4' -OH ), 2.25 [ s, 6H, 3'-N ( $\left(\mathrm{CH}_{3}\right)_{2}$ ], 2.33 ( d, 1H, H-2'” ), $2.59(\mathrm{~m}, 1 \mathrm{H}, \mathrm{H}-10), 2.84(\mathrm{~m}, 1 \mathrm{H}, \mathrm{H}-2), 3.00(\mathrm{t}, 1 \mathrm{H}$, H-4' '), 3.07 (s, 3H, 6- $\mathrm{OCH}_{3}$ ), 3.18 ( m, 1H, H-2' ), 3.29 (s, 1H, 12-OH ), 3.33 (s, 3H, 3' '- $\mathrm{OCH}_{3}$ ), $3.47\left(\mathrm{~m}, 2 \mathrm{H},-\mathrm{OCH}_{2} \mathrm{CH}_{3}\right), 3.51(\mathrm{~s}, 1 \mathrm{H}, \mathrm{H}-5$ ' ), $3.64(\mathrm{~d}, 1 \mathrm{H}, \mathrm{H}-5), 3.70(\mathrm{~m}, 1 \mathrm{H}, \mathrm{H}-8), 3.75(\mathrm{~s}, 1 \mathrm{H}$, H-11 ), 3.80 (d, 1H, H-3 ), 3.99 ( m, 1H, H-5', ), 4.33 (d, 1H, H-1' ), 4.56 (s, 1H, 11-OH ), 4.92 (d, $1 \mathrm{H}, \mathrm{H}-1$ '” ), 5.10 (dd, 1H, H-13).

${ }^{13} \mathrm{C}-\mathrm{NMR}\left(500 \mathrm{MHz}, \mathrm{CDCl}_{3}\right) \delta(\mathrm{ppm}): 1.06$ ( 2'-OTMS), $9.65\left(4-\mathrm{CH}_{3}\right), 10.64(\mathrm{C}-15), 15.11$ ( $\left.12-\mathrm{CH}_{3}\right), 15.62\left(8-\mathrm{CH}_{3}\right), 16.14\left(2-\mathrm{CH}_{3}\right), 18.87\left(10-\mathrm{CH}_{3}\right), 18.89\left(5^{\prime}{ }^{-}-\mathrm{CH}_{3}\right), 20.12\left(6-\mathrm{CH}_{3}\right)$, 21.29 ( C-14 ), 21.57 ( 5'-CH 3 ), $21.64\left(3^{\prime}{ }^{\prime}-\mathrm{CH}_{3}\right), 24.89$ ( C-8 ), 24.12, 24.67 [ -O-C $\left(\underline{\mathrm{CH}}_{3}\right) 2-\mathrm{O}-$ ], 29.45 ( C-4' ), 33.13 ( C-10 ), 34.96 ( C-2'’), 37.70 ( C-7 ), 39.71 ( C-4 ), 41.00 [ 3' -N(CH3) ${ }^{2}$ ], 45.45 ( 3' '-OCH3 ), 50.99 ( 6-OCH3 ), $56.68\left(-\mathrm{OCH}_{2} \mathrm{CH}_{3}\right), 65.68$ ( C-3' ), 65.78 (C- 5' ' ), 67.92 ( C-5' ), 70.10 ( C-11 ), 72.65 ( C-2' ), 73.24 ( C-3'’ ), 73.95 ( C-12 ), 76.86 ( C-13 ), 77.93 ( C-4'”), 78.07 ( C-3 ), 78.83 ( C-6 ), 78.96 ( C-5 ), 95.78 ( C-1'’ ), 102.85 ( C-1' ),102.87 [ -O- $\underline{\mathrm{C}}(\mathrm{CH} 3) 2-\mathrm{O}-\mathrm{]}, 170.25$ ( C-9 ), 175.83 ( C-1 ).

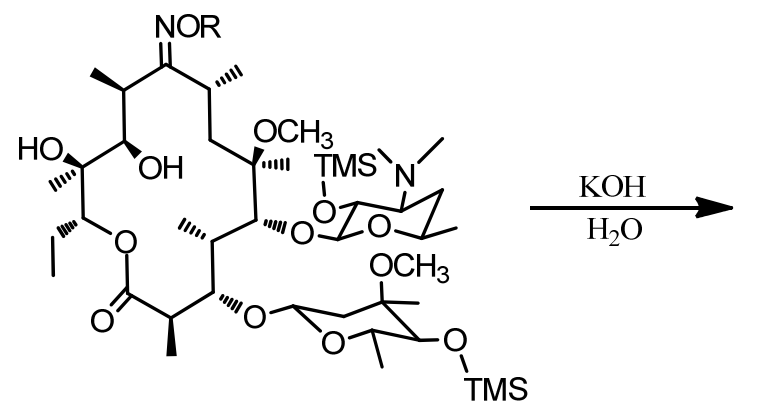

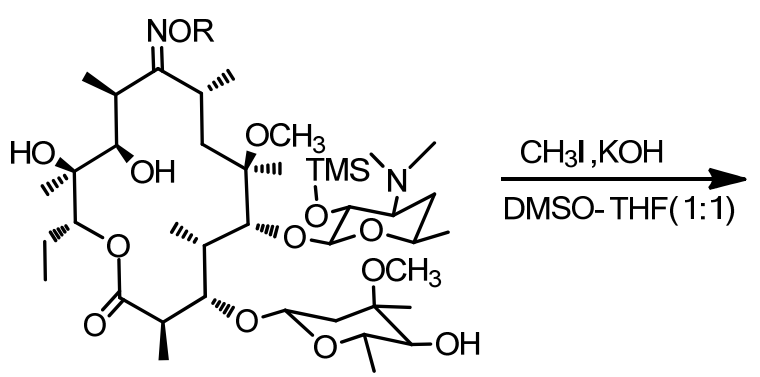

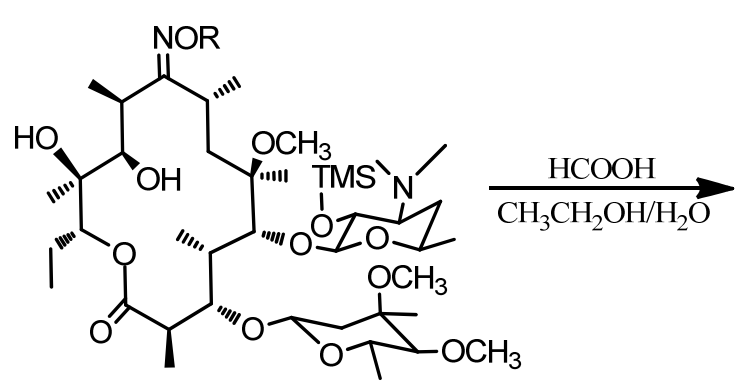

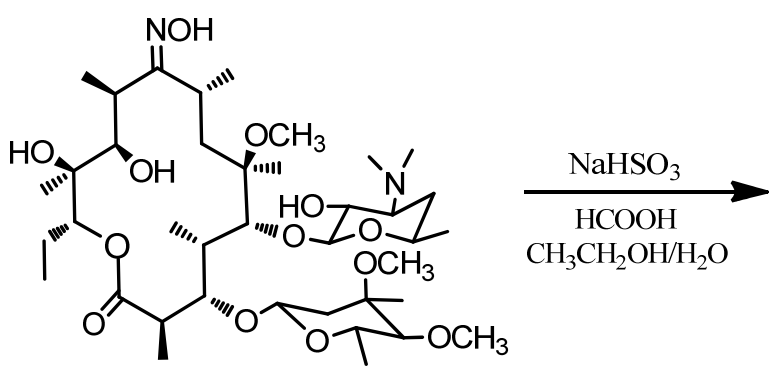

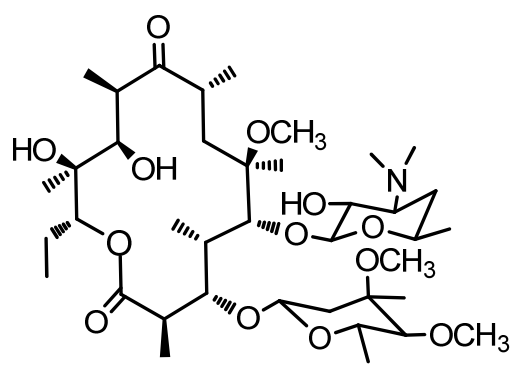

Fig.1 Synthesis pathway of 6, 4"'-Di-O-methylerythromycin A 


\section{Synthesis of 2'-O-TMS-6, 4''-Di-O-methylerythromycin A 9-[(1-ethoxy-1-methylethyl)-oxime]}

(3)

To a solution of $2(1.0 \mathrm{~g}, 1.08 \mathrm{mmol})$ in $20 \mathrm{ml}$ of a mixture of DMSO/THF $(1 / 1)$ was added $\mathrm{CH}_{3} \mathrm{I}$ $(0.5 \mathrm{ml}, 7.92 \mathrm{mmol})$ and then $85 \% \mathrm{KOH}$ powder $(0.3 \mathrm{~g}, 4.58 \mathrm{mmol})$, and the resulting mixture was stirred at room temperature for 3 hours. The solution was added $20 \mathrm{ml}$ of water; stirring was continued for 5 minutes and then extracted with petroleum ether $(40 \mathrm{ml}+20 \mathrm{ml})$. The organic layer was combined and successively washed with water and saturated brine and then dried over anhydrous $\mathrm{MgSO}_{4}$. The solvent was evaporated in vacuo to give $0.7 \mathrm{~g}(69 \%)$ of 3 as colorless foam:

${ }^{1} \mathrm{H}-\mathrm{NMR}\left(500 \mathrm{MHz}, \mathrm{CDCl}_{3}\right) \delta(\mathrm{ppm}): 0.09$ ( s, 9H, 2'-OTMS ), 0.83 ( t, 3H, H-15 ), 1.06 ( d, 3H, 8-CH3 ), 1.11 ( d, 3H, 4-CH3 ), 1.27 ( s, 3H, 3' -CH3 ), 1.29 ( d, 3H, 5',-CH3 ), 1.42 [ s, 6H, -O-C(CH3)2-O- ], 1.45 ( m, 1H, H-14 ), 1.50 ( m, 1H, H-4' ), 1.50 ( s, 3H, 6-CH3 ), 1.51 ( m, 1H, H-2'" ) 1.53 ( m, 1H, H-7 ), $1.92\left(\mathrm{~m}, 1 \mathrm{H}, \mathrm{H}-14\right.$ ), 1.97 ( m, 1H, H-4 ), 2.20 [ s, 6H, 3'-N $\left(\mathrm{CH}_{3}\right)_{2}$ ], 2.36 ( d, 1H, H-2', ), 2.50 ( m, 1H, H-3' ), 2.63 ( m, 1H, H-10 ), 2.91 ( m, 1H, H-2 ), 3.10 (s, 3H, $\left.6-\mathrm{OCH}_{3}\right), 3.14(\mathrm{~m}, 1 \mathrm{H}, \mathrm{H}-2$ ' $), 3.14(\mathrm{~s}, 1 \mathrm{H}, 12-\mathrm{OH}), 3.32\left(\mathrm{~s}, 3 \mathrm{H}, 3\right.$ ' $\left.-\mathrm{OCH}_{3}\right), 3.48(\mathrm{~m}, 2 \mathrm{H}$, $\left.-\mathrm{OCH}_{2} \mathrm{CH}_{3}\right), 3.53\left(\mathrm{~s}, 3 \mathrm{H}, 4\right.$ ' ' $\left.-\mathrm{OCH}_{3}\right), 3.56(\mathrm{~s}, 1 \mathrm{H}, 11-\mathrm{OH}), 3.56(\mathrm{~s}, 1 \mathrm{H}, \mathrm{H}-5$ ' $), 3.68(\mathrm{~s}, 1 \mathrm{H}$, H-11 ), 3.69 (d, 1H, H-5 ), 3.70 ( m, 1H, H-8 ), 3.80 (d, 1H, H-3 ), 4.22 ( m, 1H, H-5', ), 4.36 (d, $1 \mathrm{H}, \mathrm{H}-1$ ' ), 4.90 (d, 1H, H-1', ), 5.01 (dd, 1H, H-13 ).

\section{Synthesis of 6,4"'-Di-O-methylerythromycin A 9-oxime(4)}

To a solution of $3(0.7 \mathrm{~g}, 0.75 \mathrm{mmol})$ in a mixture of $20 \mathrm{ml}$ of ethanol and water $(1 / 1)$ was added to formic acid (pH4.0) and then stirred under reflux. The reaction was monitored by TLC (petroleum ether/ethyl acetate/diethylamine, 10/4/1). The resulting solution was basified (pH9-10) using 4N $\mathrm{NaOH}$ aqueous and the precipitation was washed with water. The crude product was purified by silica gel column chromatography (petroleum ether/ethyl acetate/diethylamine, 10/1/0.5) to afford $0.3 \mathrm{~g}(51.5 \%)$ of 4 as a colorless form:

${ }^{1} \mathrm{H}-\mathrm{NMR}\left(500 \mathrm{MHz}, \mathrm{CDCl}_{3}\right) \delta(\mathrm{ppm}): 0.83(\mathrm{t}, 3 \mathrm{H}, \mathrm{H}-15$ ), $0.99(\mathrm{~d}, 3 \mathrm{H}, 8-\mathrm{CH} 3$ ), 1.10 ( d, 3H, 4-CH3 ), 1.26 ( s, 3H, 3' '-CH3 ), 1.30 ( d, 3H, 5' -CH3 ), 1.45 ( m, 1H, H-14 ), 1.48 ( s, 3H, 6-CH3 ), 1.54 ( m, 1H, H-4' ), 1.59 ( $\mathrm{m}, 1 \mathrm{H}, \mathrm{H}-2$ '” ), 1.62 ( m, 1H, H-7 ), 1.94 ( m, 1H, H-14 ), 2.05 ( m, 1H, H-4 ), 2.31 [ s, 6H, 3'-N ( $\left.\mathrm{CH}_{3}\right)_{2}$ ], 2.35 ( d, 1H, H-2'” ), 2.45 ( m, 1H, H-3' ), 2.58 ( m, 1H, H-10 ), 2.95 ( m, 1H, H-2 ), 3.03 ( t, 1H, H-4”' ), 3.07 (s, 3H, 6-OCH $), 3.10(\mathrm{~s}, 1 \mathrm{H}, 12-\mathrm{OH}), 3.22$ ( m, 1H, H-2' ), 3.33 (s, 3H, 3' '-OCH $), 3.51(\mathrm{~s}, 1 \mathrm{H}, 2$ '-OH ), 3.51 ( s, 1H, H-5' ), 3.65 ( s, 3H, 4' '-OCH $\left.\mathrm{OCH}_{3}\right), 3.69$ (d, 1H, H-5 ), 3.75 (d, 1H, H-3 ) 3.86 ( m, 1H, H-8 ), , 4.04 ( m, 1H, H-5' ), 4.48 (d, 1H, H-1' ), 4.92 (d, 1H, H-1'’ ), 4.98 (dd, 1H, H-13 ).

${ }^{13} \mathrm{C}-\mathrm{NMR}\left(500 \mathrm{MHz}, \mathrm{CDCl}_{3}\right) \delta(\mathrm{ppm}): 9.30\left(4-\mathrm{CH}_{3}\right), 10.62(\mathrm{C}-15), 15.51\left(12-\mathrm{CH}_{3}\right), 16.02$ $\left(8-\mathrm{CH}_{3}\right), 17.20\left(2-\mathrm{CH}_{3}\right), 18.71\left(10-\mathrm{CH}_{3}\right), 18.71\left(5^{\prime}{ }^{-}-\mathrm{CH}_{3}\right), 19.88\left(6-\mathrm{CH}_{3}\right), 20.65(\mathrm{C}-14)$, $21.50\left(5^{\prime}-\mathrm{CH}_{3}\right.$ ), 21.54 ( 3' '- $\mathrm{CH}_{3}$ ), 25.54 ( C-8 ), 29.36 ( C-4' ), 33.39 ( C-10 ), 35.07 ( C-2')', 36.34 ( C-7 ), 38.44 ( C-4 ), 40.37 [ 3' -N ( $\left.\mathrm{CH}_{3}\right)_{2}$ ], 45.04 ( C-2 ), 49.45 ( 3'’-OCH3 ), 50.44 ( 6-OCH3 ), 62.18 ( 4'’-OCH 3 ), 65.61 ( C-3' ), 65.98 (C- 5', ), 68.55 ( C-5' ), 71.16 ( C-11 ), 71.16 ( C-2' ), 72.80 ( C-3'” ), 75.59 ( C-12 ), 77.79 ( C-13 ), 77.91 ( C-4'” ), 78.70 ( C-3 ), 79.35 ( C-6 ), 79.50 ( C-5 ), 96.28 ( C-1’’ ), 102.56 ( C-1'), 166.60 ( C-9 ), 175.83 ( C-1 ).

\section{Synthesis of 6, 4''-Di-O-methylerythromycin A(5)}

To a solution of $4(0.3 \mathrm{~g}, 0.39 \mathrm{mmol})$ in a mixture of $20 \mathrm{ml}$ of ethanol and water $(1 / 1)$ was added to $\mathrm{NaHSO}_{3}$ and formic acid (pH4.0) and then stirred under reflux. The reaction was monitored by TLC (petroleum ether/ethyl acetate/diethylamine, 10/4/1). The resulting solution was basified (pH9-10) using $4 \mathrm{~N} \mathrm{NaOH}$ aqueous and the precipitation was washed with water and afford $0.2 \mathrm{~g}$ of $5(68.0 \%)$ as colorless crystals (the purity was $77.4 \%$ determined by HPLC):

${ }^{1} \mathrm{H}-\mathrm{NMR}\left(500 \mathrm{MHz}, \mathrm{CDCl}_{3}\right) \delta(\mathrm{ppm}): 0.85(\mathrm{t}, 3 \mathrm{H}, \mathrm{H}-15), 1.11(\mathrm{~d}, 3 \mathrm{H}, 8-\mathrm{CH} 3), 1.12(\mathrm{~d}, 3 \mathrm{H}$, 4-CH3 ), 1.28 ( s, 3H, 3' '-CH3 ), 1.30 ( d, 3H, 5' -CH3 ), 1.41 ( s, 3H, 6-CH3 ), 1.53 ( m, 1H, 
H-14 ), 1.57 ( m, 1H, H-4' ), 1.65 ( m, 1H, H-2’’ ), 1.78 ( m, 1H, H-7 ), 1.86 ( m, 1H, H-14 ), 2.07 ( m, 1H, H-4 ), 2.27 [ s, 6H, 3'-N( $\left.\left.\mathrm{CH}_{3}\right)_{2}\right], 2.38$ ( d, 1H, H-2'’ ), 2.54 ( m, 1H, H-3' ), 2.64 ( m, 1H, H-10 ), 2.98 ( m, 1H, H-2 ), 3.04 ( m, 1H, H-4' '), 3.13 (s, 3H, 6-OCH $), 3.15$ (s, 1H, 12-OH ), 3.17 ( m, 1H, H-2' ), 3.32 (s, 3H, 3' '- $\left.\mathrm{OCH}_{3}\right), 3.45$ ( s, 1H, H-5' ), 3.45 ( s, 1H, 2'-OH ), 3.54 ( s, 3H, 4' '-OCH3 ), 3.67 (d, 1H, H-5 ), 3.69 ( m, 1H, H-3 ), 3.77 ( m, 1H, H-8 ), 4.22 ( m, 1H, H-5', ), 4.51 (m, 1H, H-1' ) , 4.91 (d, 1H, H-1'’ ), 5.43 (d, 1H, H-13 ).

\section{Results}

Absence of 4"'-OTMS in compound 2 was indicated by the absence of corresponding absorptions in the ${ }^{1} \mathrm{H}-\mathrm{NMR}$ and ${ }^{13} \mathrm{C}-\mathrm{NMR}$ spectra $(15 \mathrm{ppm}$ and $0.86 \mathrm{ppm}$, respectively). The ${ }^{1} \mathrm{H}-\mathrm{NMR}$ spectrum also showed a $\delta$ value of $2.19 \mathrm{ppm}$ for 4 ' '-OH, suggesting that 4'-OTMS has been taken off in compound 2, it can be determined that compound 2 was 2'-O-TMS-6-Omethylerythromycin A 9-[(1-ethoxy-1-methylethyl)oxime].

The ${ }^{1} \mathrm{H}-\mathrm{NMR}$ spectrum showed that the peak at 2.19ppm $(\mathrm{m}, 1 \mathrm{H}, 4$ ' $-\mathrm{OH})$ had disappeared and a new peak at $3.53 \mathrm{ppm}\left(\mathrm{s}, 3 \mathrm{H}, 4\right.$ ' ' $\left.-\mathrm{OCH}_{3}\right)$ had appeared in compound 3 compared to compound 2 , indicating that compound 3 is 2'-O-TMS-6,4'"-Di-O-methylerythromycin A 9- [(1-ethoxy-1-methylethyl)oxime].

In ${ }^{1} \mathrm{H}-\mathrm{NMR}$ spectrum, chemical absorptions of $0.09,1.42$ and $3.48 \mathrm{ppm}$ were vanished, suggesting that 2'-OTMS and $-\mathrm{O}-\mathrm{C}\left(\mathrm{CH}_{3}\right)_{2}-\mathrm{O}-\mathrm{CH}_{2} \mathrm{CH}_{3}$ were taken off from compound 3. In ${ }^{13} \mathrm{C}-\mathrm{NMR}$ spectrum, disappearance of corresponding chemical absorptions of 2'-OTMS, -O-C$\left(\mathrm{CH}_{3}\right)_{2}-\mathrm{O}-,-\mathrm{O}-\mathrm{C}\left(\underline{\mathrm{CH}_{3}}\right)_{2}-\mathrm{O}-,-\mathrm{O}-\underline{\mathrm{CH}}_{2} \mathrm{CH}_{3}$ ( $\delta$ value : 1.06, 102.87, 24.12 and 26.57, 56.68ppm, respectively) with other chemical shifts basically unchanged in compound 4 compared to compound 3 , suggesting that compound 4 was 6,4"-Di-O-methylerythromycin A 9-oxime.

\section{Discussion}

In the synthesis of 6, 4"-Di-O-methylerythromycin A and its derivatives, temperature is a crucial issue. The reaction proceeds very slowly and is incomplete when the temperature is too low, while the temperature is too high, much more side effects will occur. For instance, 1 was no longer reduced after one week at $10^{\circ} \mathrm{C}$, suggesting that the reaction was terminated but the raw material was not completely reacted. However, it would generate a lot of 6-O-methylerythromycin A 9-[(1-ethoxy-1-methylethyl) oxime] instead of 2 when the temperature was $40^{\circ} \mathrm{C} ; 2$ generated a variety of byproducts rather than 3 at room temperature in the methylation reaction.

Reaction time is very important on synthesis of 6, 4"-Di-O-methylerythromycin A and its derivatives. 1 generated a large number of 2 and a small amount of 6-O-methylerythromycin $\mathrm{A}$ 9-[(1-ethoxy-1-methylethyl)oxime] after 3 days at $25^{\circ} \mathrm{C}$ but a lot of 2 would be converted into 6-O-methylerythromycin A 9-[(1-ethoxy-1-methylethyl)oxime] after 5 days. It would generate a lot of unknown byproducts when the reaction time was too long in the reaction from 4 to 5 , which resulting in the amount of target product reduced. Therefore, it is extremely important to control reaction time.

\section{Conclusion}

6,4"-Di-O-methylerythromycin A and its derivatives were synthesized in $18.2 \%$ overall yield from 2',4"-O-bis(TMS)-6-O-methylerythromycin A 9-[(1-ethoxy-1-methylethyl)oxime] in this study and their structures were confirmed by ${ }^{1} \mathrm{H}-\mathrm{NMR}$ and ${ }^{13} \mathrm{C}-\mathrm{NMR}$. The control of temperature and reaction time is significantly important in order to get a high yield of the target products. Further studies on optimization of the reaction conditions are needed to obtain a higher yield of 6,4"'-Di-O-methylerythromycin A and its derivatives. 


\section{Acknowledgement}

In this paper, the research was sponsored by the Major Projects of National Science and Technology (Project No. 2009ZX09313-027).

\section{References:}

[1] Morimoto S, Takahashi Y, Watanabe Y, et al. Chemical modification of erythromycin II .Synthesis and antibacterial activity of O-alkyl derivatives of erythromycin A [J]. The Journal of Antibiotics, 1990, 43: 286-294.

[2] Yilmaz O, Demiray E, Clinical role and importance of fluorescence in situ hybridization method in diagnosis of $\mathrm{H}$ pylori infection and determination of clarithromycin resistance in $\mathrm{H}$ pylori eradication therapy [J]. World Journal of Gastroenterology, 2007, 13(5): 671-675.

[3] Sasaki J, Mizoue K, Moromoto S, et al. Microbial transformation of 6-O-methyl erythromycin derivatives [J]. The Journal of Antibiotics, 1988, 41: 908-915.

[4] Adachi T, Morimoto S, Kondoh H, et al. 14-hydroxy-6-O-methylerythromycins A, active metabolites of 6-O-methylerythromycin A in human[J]. The Journal of Antibiotics, 1989 ,41: 966-975.

[5] Watanabe Y, Morimoto S, Goi M, et al. Chemical modification of erythromycin XII. A facile synthesis of clarithromycin (6-O-methylerythromycin A) via 2'-silyethers of erythromycin A derivatives [J]. The Journal of Antibiotics, 1993, 36(2): 243.

[6] Watanabe Y, Masato K, Toshifumi A, et al. Chemical modification of erythromycin XI. Synthesis of clarithromycin (6-O-methylerythromycin A) via erythromycin A quaternary ammonium salt derivatives [J]. Heterocycles, 1993, 36:243-247.

[7] Sun Li-quan, Zhang Yu-wen, Fan Xin-yuan, et al. Research progress of related substances of clarithromycin [J]. Huaxue Shiji, 2012, 34(12): 1083-1088.

[8] Sun Jing-guo, Liang Jian-hua, Yao-Guowei, et al. Progress in synthesis of clarithromycin [J]. Chinese Journal of Organic Chemistry, 2002, 22(12): 951-963.

[9] Zheng Shao-jun, Bai Jing-rui, Yao Guo-wei, et al. Deprotective reaction in the synthesis of clarithromycin [J]. Fine Chemicals, 2004, 21(3): 185-187. 